\section{(d) JSI}

E-ISSN: 2622-1837

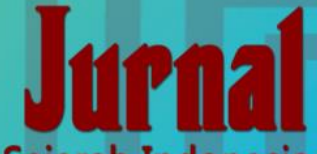

Pendidikan Sejarah Indonesia

\title{
PEMANFAATAN SITUS PURBAKALA CANDI MUARO JAMBI SEBAGAI OBJEK PEMBELAJARAN SEJARAH LOKAL DI ERA DIGITAL
}

\author{
M. Afrillyan Dwi Syahputra*, Sariyatun, Deny Tri Ardianto \\ afrillyandwis@student.uns.ac.id
}

Prodi Pascasarjana Pendidikan Sejarah, Universitas Sebelas Maret, Indonesia

\begin{abstract}
This study aims to analyze the use of Muaro Jambi temple site as an object of local history learning in the digital era. The problems discussed in the article are: (1) How does the Muaro Jambi Temple can be used as local history object of study? (2) How does the Muaro Jambi Temple could be used as the object of local history learning in digital era? To answer the two problems, authors conducted literature study method by collecting several articles from research results related to the research theme. Data collection is done by analyzing the source documents and literature. The results of this study indicate that the use of historical relics in the surrounding environment can lead to effective learning, coupled with the application of local history learning material using interactive media that follows the times, such as videos, digital books, and the internet. In addition to giving rise to effective, interesting, and interactive learning, of course, the purpose of this utilization is to increase historical knowledge of learners, especially on local historical material.
\end{abstract}

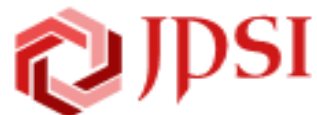

ARTICLE INFO:

Research Article

Article history:

Received 31 May 2020

Revised 16 June 2020

Accepted 19 June 2020

Published 30 June 2020

Available online 30 Juni 2020

(C)2020. JPSI. All rights reserved.

Keywords: Muaro Jambi Temple, local history, learning media

\section{PENDAHULUAN}

Bertumbuhnya globalisasi memunculkan generasi millennial. Generasi ini ialah sekelompok masyarakat yang terutama kalangan muda dan tidak dapat dilepaskan dari perangkatnya sebagai bagian yang selalu melekat dalam situasi apapun (Wahana, 2015:14), yang oleh Naisbit (2002:25) disebut sebagai era high tech, high touch yang berarti menjadikan berbagai alat teknologi sebagai bagian penting dalam kehidupan Hal ini juga membawa pendidikan terseret ke dalam perubahannya, salah satunya ialah pada pembelajaran sejarah yang dituntut menjadi lebih inovatif dan menarik. 
Akan tetapi, selama ini pembelajaran sejarah di sekolah maupun di institusi masih banyak yang belum inovatif dan hanya mengandalkan kemampuan guru untuk mentransfer ilmu yang dimilikinya sehingga menimbulkan beberapa permasalahan.

Kajian yang dilakukan oleh Santosa (2017:32) menjelaskan bahwa proses belajar mengajar sejarah banyak ditemukan berbagai permasalahan yaitu (1) proses pembelajaran yang kaku, hanya berlangsung satu arah, (2) guru sejarah kurang paham akan filosofi dari pendidikan sejarah, (3) kurangnya pemahaman guru akan posisi serta kedudukan pendidikan sejarah. Untuk mengatasi permasalahan dalam pembelajaran sejarah, Ainina (2014:40) menyarankan penggunaan media yang interkatif dan berbasis media visual dapat lebih diminati oleh siswa.

Pembelajaran sejarah juga dapat menjadi lebih menarik jika dikontekstualisasikan dengan lingkungan sekitar, misalnya melalui sejarah lokal. Namun sayangnya sejarah lokal sering diabaikan (Harrison, 2009:6). Nichols (1930:53) mengatakan anak-anak muda belum banyak mengetahui tentang kejadian lokal, untuk menghargai sejarahnya, atau untuk mengetahui signifikansi mereka yang besar padahal bisa jadi sejarah di lingkungan mereka merupakan bagian penting dari sejarah nasional.

Sejarah lokal dapat diartikan sebagai kejadian masa lalu dari kelompok masyarakat tertentu dari letak geografis tertentu, terkandung suatu peristiwa dalam lokasi yang kecil baik desa atau tempat tertentu atau wilayah administratif seperti kota dan kabupaten. Kata lokal itu berarti menunjukan tempat atau wilayah, lokal tidak identik dengan nama kota karena lokal itu sendiri dapat juga menceritakan sebuah kelompok masyarakat (Purnamasari dan Wasino 2011).

Peninggalan sejarah dapat menjadi objek kajian dari sejarah lokal. Di Indonesia sendiri terdapat peninggalan-peninggalan wujud budaya, baik berupa benda maupun tak benda yang banyak diwariskan dari generasi ke generasi melalui cerita-cerita rakyat. Temuan arkeologi di Provinsi Jambi khususnya di Desa Muaro Jambi yang merupakan peninggalan wujud budaya yaitu Candi Muaro Jambi merupakan peninggalan zaman Hindu-Budha di Jambi yang sudah ada sejak Abad ke 7-13 M (Utomo, 2011:57). Kompleks Percandian Muaro Jambi dinobatkan menjadi kompleks percandian agama Hindu-Buddha yang teluas di Indonesia dan kemungkinan besar merupakan peninggalan Kerajaan Sriwijaya dan Kerajaan Melayu. Kompleks percandian in berada di Kecamatan Muaro Sebo, Kabupaten Muaro Jambi, Provinsi Jambi, tepatnya di tepi sungai Batanghari, kurang lebih 26 kilometer dari arah timur Kota Jambi. Munoz (2006) dalam penelitiannya mengatakan bahwa Candi Muaro Jambi merupakan kompleks candi yang terbesar dan yang paling terawat di pulau Sumatera. Situs ini dilatarbelakangi oleh kebudayaan Melayu Budhis. Sedangkan kerajaan tua yang dipercaya berpusat di Muaro Jambi ialah kerajaan Mo-lo-you (Melayu) dan Sriwijaya situs Muaro Jambi terkenal dengan sebutan Komplek Percandian Muaro Jambi (Saudagar, 2003). Ada pula pendapat yang menyatakan bahwa nama kota Chaiya berasal dari kata "Cahaya" dalam bahasa Melayu. Ada pula yang percaya bahwa nama Chaiya berasal dari Sri Wijaya, dan kota ini adalah pusat Sriwijaya. Teori ini kebanyakan didukung oleh sejarawan Thailand meskipun secara umum teori ini dianggap kurang kuat (Chirayu, 1967). 
Pada tahun 1976 Direktorat Sejarah dan Purbakala mulai melakukan pembersihan terhadap tanaman-tanaman liar yang tumbuh di atas bangunan kuno secara bertahap, sampai tahun 2003 telah teridentifikasi kurang lebih 110 bangunan candi baik yang telah dipugar, belum dipugar maupun masih dalam bentuk manapo. Sampai saat ini baru 10 candi yang telah dipugar, yaitu: Candi Kedaton, Candi Tinggi, Candi Gedong I, Candi Gedong II, Candi Teluk, Candi Gumpung, Candi Kembar Batu, Candi Astano, Candi Kotomahligai dan Kolam Telagorajo. Salah satu candinya adalah Candi Gumpung ditemukan pada tahun 1820, dan dilakukan pemugaran pada tahun 1982 sampai dengan 1988. Candi ini adalah salah satu candi terbesar yang telah selesai dipugar di Komplek Percandian Muaro Jambi. Saat Pemugaran tahun1982 - 1988, beberapa temuan penting seperti arca Prajnaparamita, dan Padmasana Bata, Peripih Candi, Waira, serta potongan gelang perunggu yang semua temuan tersebut berada di museum situs Candi Muaro Jambi (Saudagar, 2003).

Situs Candi Muaro Jambi dengan berbagai macam candi yang terdapat di dalamnya berpotensi untuk dijadikan sebagai sumber belajar sejarah khususnya pada materi sejarah lokal Jambi, karena di dalam Situs Candi Muaro Jambi terdapat bukti-bukti konkret peninggalan sejarah dan agama Buddha yang memberikan gambaran tentang kerajaan Sriwijaya pada masanya. Potensi ini dapat dimanfaatkan menjadi landasan pembelajaran sejarah untuk membangun rasa cinta terhadap daerah.

Hal ini tidak lepas dari kegunaan sejarah yang dapat membentuk wawasan historis atau pandangan sejarah yang menampilkan kontinuitas dari segala sesuatu (Kartodirjo, 1993:51). Hal ini dibenarkan oleh Vubo (2003:598) yaitu sejarah terkait erat dengan struktur sosial dan politik internal di satu sisi, dan lainnya terkait erat dengan pembangunan negara bangsa di sisi lain. Selain itu, sejarah merupakan mata pelajaran yang khusus, karena materi yang dibahas adalah peristiwa yang terjadi di masa lalu dan sekarang sudah hilang. Secara akademik, pelajaran sejarah bertanggung jawab untuk mendidik para siswa agar mampu memahami dan menjelaskan berbagai fenomena historis yang dikaji (Purwanta, 2019).

Pendapat di atas juga telah diperjelas oleh Permendiknas No. 22 Tahun 2006 yang menjelaskan bahwa standar isi pada satuan pendidikan dasar dan menengah yaitu sejarah adalah cabang ilmu pengetahuan yang mengkaji mengenai asal usul juga perkembangan masyarakat yang ada pada masa lampau berdasarkan pada metode dan metodologi tertentu. Mempelajari sejarah diproyeksikan untuk mencapai suatu tujuan menumbuhkan kesadaran berbangsa dan bernegara serta bangga dan cinta akan tanah air. Mempelajari sejarah tidak serta merta mempelajari tahun, tempat, dan nama tokoh, tetapi mempelajari sejarah sesungguhnya ialah mengamalkan nilai dari sebuah peristiwa kesejarahan. Fungsi utamanya ialah untuk meningkatkan pengertian dan pemahaman secara mendalam yang baik tentang masa lampau dan juga hubungannya dengan masa depan atau yang bisa dikenal sebagai kesadaran sejarah.

Dalam arti luas, kesadaran sejarah dapat berfungsi dalam berbagai aspek sosial yang berguna bagi kehidupan. Sejarah dapat memungkinkan kita untuk menggambarkan masa sekarang melalui kejadian masa lalu, oleh karena itu kita akan dapat merencanakan bahkan memprediksi masa depan 
(Elijah, 2017:3). Dengan demikian, kesadaran sejarah tidak hanya untuk mengingat kejadian kelam di masa lalu seperti peperangan, kekalahan, dan kehancuran, melainkan kesadaran sejarah ialah untuk mengambil hikmah dari setiap kejadian di masa lalu sebagai pemacu semangat perjuangan untuk memperkuat identitas bangsa, dan rasa cinta tanah air serta lingkungan sekitarnya. Dalam kaitannya dengan hal ini situs purbakala Candi Muaro Jambi dapat dimanfaatkan keberadaannya sebagai identitas dari sejarah lokal di Provinsi Jambi, tepatnya di Kabupaten Muaro Jambi. Proses pembelajaran, terutama di wilayah Jambi, dapat memanfaatkan situs purbakala tersebut. Meskipun demikian, belum banyak penelitian yang mengulas mengenai pemanfatan situs tersebut untuk pembelajaran sejarah.

Sejalan dengan pemaparan di atas, fokus penelitian ini sendiri bertujuan untuk: (1) menjelaskan Candi Muaro Jambi dapat menjadi objek kajian sejarah lokal, dan (2) mendeskripsikan saran pemanfaatan Candi Muaro Jambi sebagai sumber pembelajaran sejarah lokal di era digital.

\section{METODE}

Metode yang digunakan ialah studi literatur. Metode kepustakaan ini (literature study) dikenal dengan metode pengumpulan data berlandaskan buku-buku, artikel ilmiah, jurnal, serta sumber tertulis yang memiliki relevansi dengan permasalahan yang dikaji. Peneliti menganalisis data yang diperoleh melalui strategi analisis data kualitatif deskriptif (Sugiyono, 2014:114). Kemudian John Creswell (2016:4) turut mengatakan bahwa penelitian kualitatif deskriptif ialah cara untuk mengesplorasi dan menungkap makna yang dianggap berasal dari masalah-masalah sosial. Dengan memanfaatkan dokumentasi untuk mengumpulkan informasi yang relevan dan berkaitan dengan masalah yang akan diteliti.

Sejalan dengan pernyataan di atas, Zed (2014) menuturkan bahwa pada riset pustaka, penelusuran pustaka tidak hanya untuk langkah awal mempersiapkan kerangka penelitian, akan tetapi sekaligus memanfaatkan sumber-sumber pustaka untuk memperoleh data penelitian. Review literatur ini bertujuan untuk membangun dan mengonstruksi konsepsi secara lebih kuat berbasis penelitian-penelitiam empiris yang relevan dan pernah dilakukan. Dalam studi ini peneliti memetakan buku-buku, hasil penelitian yang dimuat dalam artikel maupun skripsi yang kajiannya berkaitan dengan pemanfaatan situs sejarah dan pembelajaran digital yang menggunakan sumber belajar sejarah lokal seperti candi.

Adapun tahapan-tahapan yang dilakukan oleh peneliti mengikuti pendapat Bungin (2010:264) sebagai berikut: (1) mengumpulkan data awal seperti buku, artikel ilmiah, jurnal, dan sumber tertulis lainnya yang relevan dengan tema kajian, (2) mengolah data dengan menguraikan secara singkat korelasi antar kategori yang dianalisis melalui reduksi data, (3) menarik kesimpulan awal yang bersifat sementara dan dapat berubah jika ditemukan kembali fakta-fakta yang kuat pada pengumpulan data, (4) menguji keabsahan hasil penelitian dengan triangulasi sumber data, dan (5) penarikan kesimpulan hasil penelitian. 


\section{HASIL DAN PEMBAHASAN}

\section{Candi Muaro Jambi Sebagai Objek Kajian Sejarah Lokal}

Sejarah lokal ialah suatu gambaran penulisan sejarah dalam lingkup suatu wilayah yang memiliki kelokalitasan tertentu atau sering juga dikenal dengan unsur spasial (Widja, 1991:13). Akademisi di Indonesia juga menyebut sejarah lokal sebagai sejarah daerah. Sejarah lokal bersifat jamak yang berarti sejarah lokal memiliki dimensi yang beragam. Hal ini memiliki makna bawah sejarah lokal adalah sejarah dari suatu tempat, suatu "locality", yang batasannya ditentukan oleh perjanjian yang diajukan penulis sejarah (Abdullah, 1985). Pengertian ini tidak jauh berbeda dengan apa yang dikemukakan oleh Carrol (2003:4) yang menyatakan bahwa:

"I see local history as the study of the past events, or people or groups, in a given geographic area. A study based on a wide variety of documentary evidence and placed in a comparative context that should be both regional and national".

Sementara Wasino (2009) menjelaskan bahwa posisi sejarah lokal ruang lingkupnya ada di bawah sejarah nasional. Kendati demikian, sejarah lokal tidak semuanya harus berkaitan dengan sejarah nasional. Sejarah lokal bisa saja merangkup peristiwa yang memiliki hubungan dengan peristiwa sejarah yang lebih besar seperti regional, nasional, bahkan internasional.

Sejalan dengan pendapat di atas, dalam penelitian Austiningsih dan Pamungkas (2018a:56) dijelaskan bahwa mempelajari sejarah lokal dapat memberi pemahaman tentang akar sejarahnya dan dapat memahami perkembangan masyarakat pada tingkat lokal. Sejalan dengan hal ini, maka Candi Muara Jambi yang ada di Provinsi Jambi memiliki peran penting dalam perkembangan masyarakat Jambi. Namun dalam kenyataannya, penelitian dari Agustiningsih dan Pamungkas (2018b) menemukan masih banyaknya peserta didik yang belum sepenuhnya memahami tentang sejarah, fungsi dan manfaat Candi Muaro Jambi secara umum. Maka dari itu informasi yang mendalam tentang candi ini sangat diperlukan guna menumbuhkan kesadaran sejarah peserta didik pada era sekarang dengan cara yang modern pula sehingga peserta didik dapat menggali kearifan lokal yang ada di Provinsi Jambi secara menyenangkan.

Nilai-nilai yang terkandung dalam unsur kebudayaan harus senantiasa diserap oleh setiap warga negara Indonesia supaya dapat membedakan budaya satu dan lainnya. Nilai suatu kebudayaan merupakan tahapan tertinggi dari adat istiadat serta dapat memberikan identitas dari karakter bangsa dan kelompok masyarakat. Nilai budaya tidak dapat digantikan dalam waktu yang cepat oleh budaya lain (Ritonga, 2012:249). Usaha untuk memperkenalkan dan menginternalisasikan nilai budaya ini dapat dilakukan melalui pembelajaran sejarah lokal.

Pembelajaran sejarah lokal di Candi Muaro Jambi bertujuan agar peserta didik dapat mengetahui dan memahami asal-usul daerah tempat tinggalnya dan mengenal lingkungannya sebagai tempat bersejarah. Hal ini sesuai dengan tujuan pembelajaran sejarah lokal yang dikatakan oleh Mulyana (2007) bahwa sejarah lokal mampu mengenalkan mahasiswa terhadap peristiwaperistiwa di daerahnya yang sangat berguna. Dengan mengenal karya dan peninggalan leluhur 
Nusantara dari Kerajaan Sriwijaya maka diharapkan siswa atau mahasiswa sebagai peserta didik dapat menimbulkan rasa cinta tanah air yang salah satu akarnya adalah dengan kecintaan pada berbagai situs, monumen, candi, dokumen, arca, dan berbagai peninggalan sejarah lainnya sebagai bagian integral dari memori kolektif setiap anak bangsa.

Dari paparan di atas, tidak dapat diragukan bahwa Situs Purbakala Candi Muaro Jambi layak dijadikan sumber belajar sejarah yang bersifat lokal, dan kemudian dapat diperkenalkan di mata nasional bahkan internasional. Sejarah panjang dari peninggalan ini sendiri ialah bukti nyata bahwa kebudayaan di Provinsi Jambi dan Indonesia sangat kaya. Situs ini memiliki nilai kesejarahan yang tak ternilai harganya yang merupakan jejak sejarah yang telah terjadi di Provinsi Jambi serta menjadi identitas dan ciri khas daerah Jambi sebagai warisan Kerajaan Sriwijaya yang kekuasaannya hingga sampai ke semenanjung Malaya hingga Thailand.

Sejalan dengan hal tersebut, maka sejarah di Desa Muaro Jambi yang berkaitan dengan Candi Muaro Jambi harus digali dan diekspos sehingga yang diharapkan menambah khazanah sejarah lokal, nasional, maupun internasional. Hal ini merupakan bagian dari upaya menjadikan daya tarik wisata situs percandian Muaro Jambi masuk kedalam warisan dunia yang telah di rencanakan sejak tahun 2010. Bahkan sebelumnya Candi Muaro Jambi merupakan destinasi wisata yang di unggulkan Pemprov Jambi sebagai destinasi wisata unggulan (primary tourism destination), dan sebagai warisan budaya yang menumental peradaban Buddha yang diikutsertakan dalam civilitation trail pada deklarasi Borobudur oleh enam Negara ASEAN yaitu Thailand, Myanmar, Kamboja, Vietnam, Laos dan Indonesia pada tahun 2006 (Pamungkas, 2018: 49).

Bangsa Indonesia patut berbangga diri karena memiliki keanekaragaman sumber daya yang tak habis-habisnya untuk digali oleh siapapun. Keberagaman budaya serta peninggalan yang tersebar dari Sabang sampai Merauke. Mulai dari kebudayaan fisik hingga non-fisik yang diwariskan secara turun temurun melalui cerita rakyat. Salah satunya ialah temuan arkeologi di Provinsi Jambi di Desa Muaro Jambi yang merupakan bukti nyata wujud budaya Hindu-Buddha yaitu Candi Muaro Jambi yang ada sejak abad ke VII - XIII M (Utomo, 2011: 57). Sudah seharusnya pemerintah memberikan perhatian lebih dan mengangkat Candi Muaro Jambi ini sebagai sejarah lokal yang dapat dimanfaatkan dengan maksimal ke dalam pembelajaran sejarah lokal di daerah.

Dari paparan pembasahan di atas, Candi Muaro Jambi sebagai peninggalan sejarah ini sangat penting untuk di lestarikan dan dihargai sebagai suatu warisan kerajaan Sriwijaya yang sangat penting untuk diperhatikan seluruh rakyat Indonesia. Maka dari itu Candi dapat dikatakan sebagai obyek kajian sejarah lokal yang patut untuk dilestarikan.

\section{Saran Pemanfaatan Candi Muaro Jambi sebagai Sumber Pembelajaran Sejarah Lokal di Era Digital}

Pada dasarnya, sasaran pemanfaatan Candi Muaro Jambi untuk pembelajaran sejarah lokal ini sendiri mencakup berbagai tingkatan sekolah di Indonesia, yaitu pada sekolah menengah pertama (SMP) kelas VII pada matapelajaran IPS yang sesuai dengan Kompetensi Dasar (KD) 3.4 Memahami kronologi perubahan dalam kehidupan bangsa sejak masa praaksara sampai Hindu-Buddha, 
Kemudian pada sekolah menengah atas (SMA) pada matapelajaran Sejarah Indonesia kelas X KD 3.6 Menganalisis perkembangan kehidupan masyarakat dan budaya pada masa kerajaan HindduBuddha pada sejarah wajib kelas XI SMA. Sedangkan untuk perguruan tinggi yaitu pada mata kuliah Sejarah Lokal, misalnya di Prodi Pendidikan Sejarah Universitas Jambi pada semester empat. Selain itu penelitian Suryani (2018:234) yang mengungkapkan nilai-nilai sejarah lokal dalam Candi Muaro Jambi yang dapat diimplementasikan dalam kehidupan bermasyarakat sehingga pemanfaatannya lebih luas dalam hal pembelajaran.

Pembelajaran tentu membutuhkan media yang interaktif, terlebih lagi pada mata pelajaran sejarah yang sering kali dianggap membosankan. Penggunaan media dapat memperjelas pesan menjadi suatu yang nyata, tidak berbasis teks dan buku, memangkas ruang, waktu, tenaga, dan biaya. Berkembangnya teknologi membawa perubahan terhadap segala bidang termasuk pendidikan. Dibutuhkan kreativitas tenaga pengajar dalam merenapkan pembelajaran sejarah yang menarik. Pada era Pendidikan 4.0 ini pembelajaran sejarah dituntut untuk mengombinasikan apa yang ada di masa lalu dengan perkembangan teknologi masa sekarang. Sebagai contoh Situs Purbakala Candi Muaro Jambi yang dapat dipergunakan sebagai sumber ataupun media pembelajaran sejarah maupun sejarah lokal di era digital.

Hal yang patut diketahui dalam pemilihan sumber belajar harus memperhatikan kriteria, ekonomis, praktis, fleksibel, dan sesuai dengan tujuan. Lingkungan dapat menjadi salah satu sumber belajar yang penting dan memiliki nilai-nilai yang berharga untuk menambah khazanah pengetahuan sejarah peserta didik. Lingkungan ini terdiri dari lingkungan alam dan lingkungan sosial (Iskandar, 2009:196). Dengan membawa siswa ke lapangan seperti survey, karyawisata, praktik lapangan, guru dapat menimbulkan rangsangan minat belajar kepada siswa. Guru dapat pula memperkenalkan situs sejarah dengan memanfaatkan media seperti video, internet, e-book, dan web juga dapat memberikan pengalaman baru kepada siswa.

Sumber-sumber belajar yang telah dipaparkan di atas dapat dimanfaatkan dalam pembelajaran sejarah yang secara sistematis tersusun unsur manusiawi, material, fasilitas, perlengkapan dan prosedur yang saling berkaitan dengan sumber belajar sejarah lokal seperti Situs Purbakala Candi Muaro Jambi. Selain itu sumber-sumber sejarah untuk pembelajaran sejarah lokal ini menginisiasi guru dan siswa untuk secara mendalam memahami ulang sejarah lokal daerahnya sendiri. Karena terkadang sejarah lokal tiap-tiap provinsi sering tidak diangkat dalam sejarah nasional dan dalam buku paket siswa. Meminjam kembali pendapat dari Taufik Abdullah (1985) yang mengatakan sejarah lokal ini menyangkut aspek geografis yang merupakan tempat tinggal suatu masyarakat dan berdasarkan pada unit kecil seperti daerah, desa, dusun, dan pedukuhan.

Sejauh ini ada bermacam kegiatan dan program yang dilakukan pada Candi Muaro Jambi dalam pemanfaatan dan pengembanganya sebagai situs budaya oleh Departemen Kebudayaan dan Pariwisata (Disbudpar) Provinsi maupun daerah di kabupaten-kabupaten di Jambi terutama oleh Badan Pelestarian Cagar Budaya (BPCB) yang selalu berupaya untuk melestarikan cagar budaya (Meilania \& Febrianti, 2019:109). Selain bermanfaat di sektor pariwisata seperti yang telah dijelaskan 
di atas, yang paling penting ialah bagaimana pemafaatannya disekolah dan di instansi terkait. Permasalahannya ialah seperti yang dijelaskan Khairurizqi dkk (2015:171) bahwa berdasarkan data di lapangan, banyak remaja yang tidak mengetahui tentang Candi Muaro Jambi karena kurangnya pemberitaan tentang itu, dapat dikatakan bahwa media kurang mengangkat kajian ini. Hasil analisis solusi dari permasalahan tersebut ialah dengan membuat media informasi yang berisi materi tentang candi. Dengan adanya permasalahan di atas, hal ini menjadi landasan perlunya dilakukan pengembangan media pembelajaran agar mahasiswa maupun masyarakat dapat melihat secara nyata kondisi Candi Muaro Jambi dan temuan-temuan di sekitarnya serta sebagai bukti bahwa pendahulu mereka telah berinteraksi dengan bangsa asing pada zaman dahulu di Provinsi Jambi.

Berbagai macam penelitian pengembangan (R\&D) menggunakan video, web, e-book dll telah dilaksanakan dan terbukti meningkatkan nilai-nilai kesejarahan peserta didik seperti yang dijelaskan Purnama Sari (2011:202) bahwa pengembangan model pembelajaran studi pengajaran sejarah berdasarkan situs sejarah lokal dapat meningkatkan kualitas pembelajaran, dan situs sejarah lokal dapat digunakan sebagai salah satu bahan ajar yang efektif. Khairurizqi (2015:178) dalam penelitiannya merancang aplikasi yang membahas tentang artefak dengan menggunakan sistem Android. Konten yang terdapat dalam aplikasi adalah informasi tentang candi, informasi tentang artefak serta sejarah candi. Selain aplikasi, media pembelajaran berbasis web juga dapat dipergunakan, tetapi dib dalam penelitian Charina dkk (2012:11) ini dijelaskan bahwa penggunaan Website Muara Jambi Pilgrimage kurang mendapat perhatian dan kurang di promosikan hal ini dibuktikan bahwa intensitas pengunjungnya kurang. Tetapi untuk pemenuhan kebutuhan akan informasi yang diberikan kepada pengunjung situs baik karena memiliki informasi yang aktual serta mengikuti perkembangan di lapangan, seperti lokasi Candi Muaro Jambi, jarak tempuh, biaya perjalanan, dan lain-lain.

Dari beberapa penelitian di atas hal ini menjadi jelas bahwa peserta didik lebih senang dengan media pembelajaran sejarah yang berbasis pada teknologi yang dapat dipergunakan melalui gawai ataupun platform penampil lainnya. Dari berbagai penelitian serta pendapat ahli pada paparan di atas, kita dapat memanfaatkan apapun yang nilainya dapat di implementasikan di masyarakat. Terutama pada peninggalan-peninggalan sejarah lokal yang ada di sekitar. Candi merupakan bentuk nyatanya, sudah seharusnya dilindungi dirawat, dan tentu saja untuk di pelajari agar dapat mengembangkan pengetahuan, kemampuan, kesadaran, dan cinta tanah air Indonesia.

\section{SIMPULAN}

Candi Muara Jambi memiliki peran penting dalam sejarah perkembangan masyarakat Jambi. Dengan adanya Candi Muaro Jambi peserta didik ataupun masyarakat dapat mengetahui dan memahami asal-usul daerah tempat tinggalnya dan mengenal lingkungannya sebagai tempat bersejarah. Karena sejarah lokal mampu mengenalkan siswa terhadap peristiwa-peristiwa di daerahnya yang sangat berguna. Dengan mengenal karya dan peninggalan leluhur, dapat menimbulkan rasa cinta tanah air yang salah satu akarnya adalah dengan kecintaan pada berbagai 
situs, monumen, candi, dokumen, arca, dan berbagai peninggalan sejarah lainnya sebagai bagian integral dari memori kolektif setiap anak bangsa Indonesia

Situs Purbakala Candi Muaro Jambi layak dijadikan sumber belajar sejarah yang bersifat lokal terutama di Provinsi Jambi, dan kemudian dapat diperkenalkan di tingkat nasional maupun mancanegara. Peninggalan ini sendiri ialah bukti nyata sejarah panjang bangsa Indonesia memiliki kebudayaan yang sangat kaya dan beragam. Candi seharusnya menjadi situs yang di lindungi serta dihargai. Karna memiliki nilai kesejarahan yang tak ternilai harganya, suatu persitiwa besar yang telah

Pemanfaatan Situs Purbakala Candi Muaro jambi Sebagai Objek Pembelajaran Sejarah Lokal di Era Digital ini sangat memiliki keunggulan tersendiri bagi pembelajaran sejarah terutama pada materi Hindu-Buddha. Karna peserta didik dapat belajar sejarah dengan cara yang baru, tidak hanya terpaku pada buku sejarah, tetapi dapat mengakses informasi mengenai peninggalan sejarah melalui gawai, komputer, dan internet. Dari berbagai macam penelitian yang telah dilakukan, objek penelitian yang sebagian besar adalah siswa, guru, maupun dosen, sepakat untuk mengatakan bahwa pemanfaatan peninggalan sejarah disekitar kita dapat lebih menumbuhkan rasa cinta tanah air serta mengokohkan identitas Indonesia sebagai bangsa yang besar dan bangsa yang tidak akan pernah melupakan sejarahnya.

\section{DAFTAR RUJUKAN}

Abdullah, T. (1985). Sejarah Lokal di Indonesia. Gadjah Mada University Press.

Agustiningsih, N., \& Pamungkas, S. (2018a). Analisis Kebutuhan Pengembangan Media Pembelajaran Video Candi Muara Jambi Berbasis Sejarah Lokal Pada Mata Kuliah Sejarah Indonesia. Diakronika, 18(1), 67.

Agustiningsih, N., \& Pamungkas, S. (2018b). Pengembangan Media Video Pembelajaran Candi Muara Jambi Berbasis Sejarah Lokal Pada Mata Kuliah Sejarah Indonesia Hingga Abad 15 Program Studi Pendidikan Sejarah Universitas Batanghari Jambi. Jurnal Ilmiah Dikdaya, 8(11), 320-333.

Ainina, I. A. (2014). Pemanfaatan Media Audio Visual Sebagai Sumber Pembelajaran Sejarah. Indonesian Journal of History Education, 3(1).

Amaliya, C., Setiawan, W., \& Novianti, E. (2012). Hubungan Penggunaan Website Muara Jambi Pilgrimage dengan Pemenuhan Kebutuhan Informasi Pengumjung Situs tentang Candi Muaro Jambi. E-Jurnal Mahasiswa Universitas Padjadjaran, 1(1), 1-13.

Bungin, B. (2010). Penelitian Kualitatif. Putra Grafika.

Carrol, K. (2003). On Doing Local Historical. In Terry A. Bonhart, Forward to On Doing Local Historical; Reflections on What Historians Do, Why, and What in Means. AltaMira.

Chia, Y. T. (2012). History education for nation building and state formation: The case of Singapore. Citizenship Teaching \& Learning, 7(December), 191-207.

Chirayu, C. R. M. . (1967). Background to the Sri Vijaya Story-Part I. Journal of the Siam Society, 62(1), 174-211. 
Creswell, J. W. (2016). Research Design : Pendekatan Metode Kualitatif, Kuantitatif dan Campuran (Keempat). Pustaka Pelajar.

Darini, R. (2016). Sejarah Kebudayaan Indonesia Hindu-Budha. Ombak.

Elijah, Y. I. (2017). The Importance Of History For Nation-State: The Case Of Nigeria. Humanity Jos Journal of General Studies University of Jos, 9(1), 287.

Enam, L. (2018). Biksu Dunia Berkumpul di Candi Terluas di Asia Tenggara.

https://www.liputan6.com/regional/read/3236755/biksu-dunia-berkumpul-di-canditerluas-se-asia-tenggara\#

Febriyanti, A. N., Waluyo, H. J., \& Haryanto, S. (2017). Pengembangan Media Pembelajaran Sejarah Berbasis Media Audio Visual Situs Purbakala Pugung Raharjo Untuk Meningkatkan Kesadaran Sejarah Siswa Kelas X Sma Negeri 1 Kotagajah. Jurnal Ilmiah Dikdaya, 6(1), 29-45.

Harrison, L. H. (2009). Local history as a teaching technique. Peabody Journal of Education, January 2015, 37-41.

Iskandar. (2009). Psikologi Pendidikan Sebuah Orientasi Baru. Gaung Persada Press.

Kartodirjo, S. (1993). Pendekatan Ilmu Sosial dalam Metodologi Sejarah. Gramedia Pustaka Utama.

Khairurrizqi, Aris Rahmansyah, T. H. (2015). Perancangan Graphical User Interface "Si Jambe" Sebagai Media Pembelajaran di Jambi. Jurnal Telkom University, 2(1), 171-178.

Maryanto, D. A. (2007). Seri Fakta dan Rahasia di Balik Candi: Mengenal Candi (Pertama). Citra Aji Parama.

Meilania, M., \& Febrianti, H. (2019). Pelestarian Candi Muaro Jambi Sebagai Benda Cagar Budaya Dan Pariwisata Di Provinsi Jambi. Journal V-Tech (Vision Technology), 2(1), 99-109. https://doi.org/10.35141/jvt.v2i1.509

Mulyana, A., \& Gunawan, R. (2007). Sejarah Lokal (Penulisan dan Pembelajaran di Sekolah). Salamina Press.

Munoz, P. M. (2006). Early Kingdom of The Indonesian Archipelago And The Malay Penisula. Didier Millet PTE Ltd.

Naisbit, J. (2002). High Tech High Touch: Pencarian Makna di Tengah Perkembangan Pesat Teknologi (D. R. Basuki (ed.)). Mizan.

Nichols, H. B. (1930). The Importance Of Local History In The Schools And Methods Of Teaching It. The Quarterly Journal of the New York State Historical Association, 11(1), 53-62.

Pamungkas. (2018). Candi Muaro Jambi : Kajian Cerita Rakyat, Arkeologi, dan Pariwisata. Jurnal IImiah Istoria, 2(2), 49-62.

Purnamasari, I., \& Wasino, W. (2011). Pengembangan Model Pembelajaran Sejarah Berbasis Kabupaten Temanggung. Paramita - Historical Studies Journal, 21(2), 202-212.

Purwanta, H. (2019). Hakekat Pendidikan Sejarah. Uns Press Dan Chers. 
Ritonga, S. (2012). Orientasi Nilai Budaya dan Potensi Konflik Sosial Batak Toba Muslim dan Kristen di Sumatera Utara. Analisis: Jurnal Studi Ke-Islaman, VII(2), 249.

Santosa, Y. B. P. (2017). Problematika Dalam Pelaksanaan Pendidikan Sejarah Di Sekolah Menegah Atas Kota Depok. Jurnal Candrasangkala Pendidikan Sejarah, 3(1), 30.

Saudagar, F. (2003). Situs Sejarah Candi Muaro Jambi. FKIP Universitas Jambi Press.

Sudjana, N. (2007). Teknologi Pengajaran (Pertama). Sinar Baru Algesindo.

Sugiyono. (2014). Memahami Penelitian Kualitatif. Alfabeta.

Suryani, I. (2018). Candi Kedaton Muara Jambi Dan Nilai Karakter Dalam Pembelajaran Sejarah: Sebuah Identifikasi Awal. HISTORIA Jurnal Program Studi Pendidikan Sejarah, 6(2), 231.

Utomo, B. (2011). Kebudayaan Zaman Klasik Indonesia Di Batanghari (Pertama). Dinas Kebudayaan dan Pariwisatar Prov. Jambi.

Vubo, Y. E. (2003). Levels of Historical Awareness. Cahiers d'études Africaines, 43(171), 591-628. https://doi.org/10.400o/etudesafricaines.217

Wahana, H. D. (2015). Pengaruh Nilai-Nilai Budaya Generasi Millennial dan Budaya Sekolah terhadap Ketahanan Individu (Studi Di SMA Negeri 39, Cijantung, Jakarta). Jurnal Ketahanan Nasional, 21(1), 14.

Wasino, W. (2009). Pokok-Pokok Pikiran Untuk Penulisan Sejarah Lokal. Sarasehan Koordinasi dan Curah Pendapat Penguatan Sejarah Lokal untuk Meningkatkan Wawasan Kebangsaan Deputi Menko Kesra Bidang Koordinasi Kebudayaan Paariwisata Pemuda dan Olah Raga.

Widja, I. G. (1991). Sejarah Lokal Suatu Perspektif dalam Pengajaran Sejarah. Angkasa.

Zed, M. (2014). Metode Penelitian Kepustakaan (Pertama). Yayasan Obor Indonesia. 